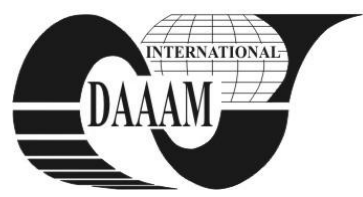

Annals of DAAAM for 2011 \& Proceedings of the 22nd International DAAAM Symposium, Volume 22, No. 1, ISSN 1726-9679 ISBN 978-3-901509-83-4, Editor B. Katalinic, Published by DAAAM International, Vienna, Austria, EU, 2011 Make Harmony between Technology and Nature, and Your Mind will Fly Free as a Bird Annals \& Proceedings of DAAAM International 2011

\title{
INTEGRATED CONTROL AND POWER ELECTRONICS FOR BLDC MOTOR
}

\author{
PAZDERA, I[vo] \& PROCHAZKA, P[etr]
}

\begin{abstract}
Current trend in drive industry is assembling all separate parts (motor, inverter, control electronic) into one compact casing. This article describes design of embedded control and power electronic of BLDC motor. The final compact drive is determined for simple pump application. Design is conformed to low manufacturing expenses and high reliability and life time in comparison with classical DC motor (Vorel, 2005).
\end{abstract}

Key words: BLDC motor, embedded control electronics, power circuit design

\section{INTRODUCTION}

The main challenge for design of the control and power electronics is predefined small size of the space of the rare motor cover for electronic system integrating. The next important restriction is the manufacturing cost which shouldn't be higher than 50 Euro (including PCBs) (Byong-Kuk, 2003). This BLDC drive should be used especially in pump application where high surroundings humidity is expected. For this reason the rare motor cover (where the whole electronic system will be placed) almost hermetically sealed, which together with high output inverter power puts high demands on discrete devices. The motor shield works as a heat sink for power devices. We have to consider the ambient temperature very similar to temperature of the heat sink. All devices have to work with high temperature (typical max. values up to $105^{\circ} \mathrm{C}$ ) with respect to high reliability of the whole system. Power devices are chosen regarding to minimal conduction losses to achieve low temperature of the heat sink. Due to small area of the motor cover is control and power electronic split into two PCBs (power and control board), see Fig.1. Profile of the both PCBs is circle with the $\varnothing 10 \mathrm{~mm}$ hole in the middle for the extended shaft

\section{INTEGRATION OF THE POWER AND CONTROL CIRCUITS TO THE MOTOR}

The whole electronic system was designed with respect to minimal manufactured expenses and was limited by small area of the rare motor cover. Reduction of the cost was focused on simplifying of the control and power topology (mosfet drivers, control ICs etc.) Exclusive motor using in pump application doesn't put any special demands on complexity of control circuits. Therefore an analog single purpose specialized integrated circuit was used for control of the BLDC motor. Finally regarding to space restrictions this solution saves some space and complexity of PCB in comparison to solution with powerful DSP processor where supportive devices and circuits are needed. There are a lot of BLDC control circuits on the market with various features (Nagy, 2009). For our purposes we can sort them according to their output mosfet drivers. There are many control circuits which have already integrated low and high side mosfet output drivers. These circuits use bypass capacitor to "galvanic" isolation of the top driver from the bottom emitor potential (Lee, 2004). These circuits can control classical three phase $\mathrm{N}$-mosfet inerter. The operational duty cycle is limited by bypass capacitor. The common duty cycle range of these circuits is usually from 10\% to $90 \%$, although we can increase this range with bigger bypass capacitor. There are some wrong experience with these circuit due to their immunity to $\mathrm{dV} / \mathrm{dt}$ and crashing level shifting transistor especially in high voltage application too. For higher current transistor the outputs of the drivers have to be powered by external amplifier very often. Although for low voltage applications are these circuits widely used solution with control IC without mosfet drivers was finally used. The mosfet driver is made from simple amplifier for enhancing current output. Pmosfets are used for top switches to avoid necessity of using galvanic isolation. This topology is convenient and possible for low voltage application. Simple output amplifier provides high reliability and especially high immunity to $\mathrm{dV} / \mathrm{dt}$. The main disadvantage of the used $\mathrm{P}-$ mosfets is higher conductive losses due to their higher resistance of $\mathrm{P}$ - channel. The whole power inverter with control and the other supportive electronic should be integrated into rare motor cover. The embedded area has cylinder profile with diameter about $160 \mathrm{~mm}$ and height about $40 \mathrm{~mm}$. Shaft with $10 \mathrm{~mm}$ diameter passes through the middle of this space limiting the electronic area additionally. So the left area for placing the PCB and devices is significantly limited especially when considering very high maximal output power of the inverter about $1,4 \mathrm{~kW}$. It is impossible to place all devices to one multilayer PCB. So the electronic was split into two PCBs one for power part and the other for control issues (Jong Sung, 2010). The transistors are fixed on the shield which is simultaneously used as a robust heat sink. All transistors are

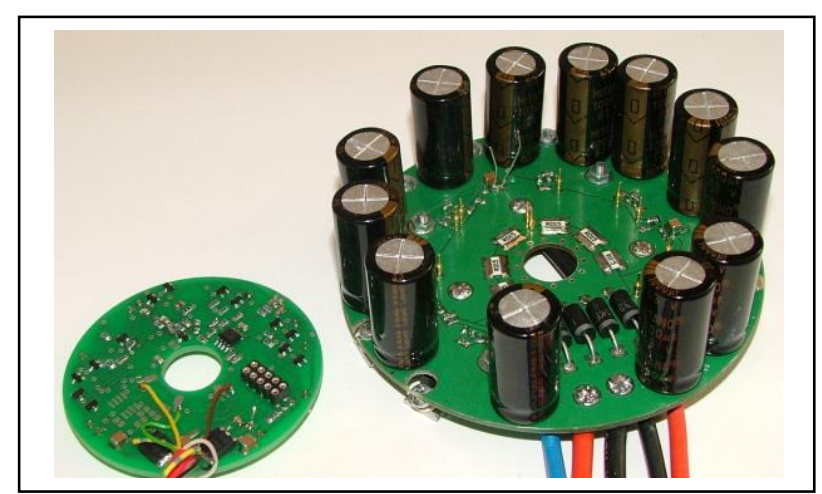

Fig.1. Power and control electronic for BLDC motor

soldered from the bottom to power PCB. On the top side around the circle are electrolytic capacitors for pulse application, transils for short time overvoltage caused by recuperating inductive energy during fault situation where all transistors are off and shunt resistors for current limiting. As it was said above in hermetical sealed motor cover is ambient temperature very similar to temperature of the heat sink. So it is important to keep this temperature at the lowest possible value. The 
durability of the devices is highly related to this temperature especially electrolytic capacitors are the most sensitive devices and special attention must be paid to their design. Rated continuous current is $30 \mathrm{~A}$ and the motor can be shortly overloaded to value $60 \mathrm{~A}$. If we take into consideration the worst possible situation where there are long cables with nonnegligible inductance between voltage source and DC capacitors of the inverter. Than we can assume, that the capacitors are stressed by high current pulses maximal value equal to nominal motor current or by even two times higher value during short-time motor overload. The real effective value of the capacitor is depended on duty cycle. It is important to know exactly this effective value to choose right number of capacitors to reduce their conductive losses caused by highly pulse current. We assume unipolar control algorithm applied on inverter, where the PWM is applied on the bottom transistor and the top transistor is permanently switched on according to actual position. There is no energy recuperation in optimal operation for this kind of pump application. The effective capacitor current is given by:

$i_{\text {Crms }}=\sqrt{\frac{1}{T} \int_{0}^{t_{o n}}\left(I_{m}(1-D)\right)^{2} d t+\int_{t_{o n}}^{T}\left(I_{m} \cdot D\right)^{2} d t}$

Applying the condition for estimation of maximum of the function $\underline{\underline{i}}_{\text {Crms }} / d D=0$ on (1), we obtain:

$$
I_{m}^{2} \cdot(1-2 D)=0
$$

From equation (2) and assuming $i_{C r m s 0}=0$ we obtain that the maximum of the capacitor current is by duty cycle $\mathrm{D}=0.5$. Than according (1) is maximal effective capacitor current $i_{\text {Crmsmax }}$ given by:

$$
i_{\text {Crmsmax }}=I_{m} \sqrt{0.25}
$$

Because the thermal capacity of electrolytic capacitor is significantly lower than the thermal capacity of the motor we have to design the DC link electrolytic capacitors for conditions during short-time overload. We can't exclude the possibility that the motor will be operating with duty cycle around 0.5 . So the capacitors are designed to hardest conditions in which the temperature can reach $105^{\circ} \mathrm{C}$. In fact it is exaggerated value and the capacitor will be mostly operating in more favorable conditions. In nominal point the temperature does not reach $50^{\circ} \mathrm{C}$. Keep the temperature under this value can ensure life time about or even more than 10000 hours for low cost capacitors. Low level of motor heating is expected . With respect to reliability is a capacitor critical device. Big influence to the final temperature of the capacitors has an ambient temperature due to hermetically sealed motor cover. Main disadvantage of our topology is high conductive losses of the Pmosfets so the other losses have to be maximally minimized. Mosfets were chosen with low resistivity of channel $(16 \mathrm{~m} \Omega$ each) and minimal switching time. $\mathrm{P}$ - mosfets currently available on the market are more limited with continuous current. For minimizing switch on resistance two P-mosfets were connected in parallel. Still they have two times higher resistivity in comparison to chosen $\mathrm{N}-\operatorname{mosfet}(3.5 \mathrm{~m} \Omega)$. The price of two half current $\mathrm{P}$ mosfets is similar to one high current $\mathrm{N}$ - mosfet. Because The lowest conductive losses are in nominal point $(\mathrm{D}=1)$ about $14 \mathrm{~W}$. The formula for conductive losses is generally known and it is not mentioned deliberately. The switching losses are reduced by choosing very fast bottom $\mathrm{N}$ - transistors where PWM is applied. Optimized formula for switching losses calculation is:

$$
\text { Switching losses }=\frac{1}{4} U_{D C} \cdot i_{m}\left(t_{o n}+t_{o f f}\right) \cdot f_{P W M}
$$

The PWM frequency was adjusted to $20 \mathrm{kHz}$ to reduce noise distortions. Higher frequency increases switching losses but reduce current (torque) ripple. Current ripple is for $20 \mathrm{kHz}$ satisfactorily. According to (4) very fast transistors reduce losses but can increase a risk of dangerous voltage overshoots. Switching losses for nominal point are about $3 \mathrm{~W}$. According to calculated total losses it is possible to design heat sink. With help of ANSYS program for thermal calculation the final temperature of the heat sink was simulated. In the nominal point of the drive can't exceed $45^{\circ} \mathrm{C}$. In the nominal point has the inverter maximal efficiency about $96 \%$. The last challenge is design of current sensing loop especially in terms of layout. Current sensing is realized by shunt resistors connected in series into the mutual ground of the bottom transistors. Range of the measured voltage signal of actual current is up to $100 \mathrm{mV}$ and is compared with comparator reference voltage. For setting of the current threshold the ripple waveform has to be taken into consideration. Such a low level voltage signal is very sensitive to interference. The layout loop of the measured signal must be strictly minimized in terms of layout dimensions.

\section{CONCLUSION}

This paper give a quick summary how to design a real single purposed industrial application with embedded electronic, low manufacturing cost, high reliability, simply and quick design procedure. Some useful recommendations and limitation during a design procedure are given. Future development of integration of the power and control electronic into one casing will continue in more complex and universal BLDC application. Analog control will be replaced by powerful DSC algorithm to provide a lot of additional features of the drive and to increase efficiency. Typical topology with only $\mathrm{N}$-transistors for reducing conductive losses will be used. New transistor drivers with high immunity to $\mathrm{dV} / \mathrm{dt}$ and based on magnetic isolation of power signal will be developed.

\section{ACKNOWLEDGEMENTS}

The contribution was partially supported by projects CZ.1.05/2.1.00/01.0014 "Center for Research and Utilization of Renewable Energy Sources" of the Ministry of Education, Youth and Sports of the Czech Republic and

\section{REFERENCES}

Byong-Kuk L., Tae-Hyung K., Ehsani M., (2003) "On the feasibility of four-switch three-phase BLDC motor drives for low cost commercial applications: topology and control," in Power Electronics, IEEE Transactions on, pp. 164-172, ISSN: 0885-8993

Jong Sung P., Jun-Hyuk Ch., Bon-Gvan G., In-Soung J., Ehsani M., (2010) "BLDC drive control of electric water pump for automotive application," in Vehicle Power and Propulsion Conference (VPPC), 2010 IEEE, pp. 1-5, ISBN: 978-14244-8220-7

Lee J.B., Choi J.H., Chung J.K., Lim J.H., Ehsani M., (2004) "Design and implementation of integrated drive circuit for a small BLDC motor," in Electrical Machines and Systems, 2003. ICEMS 2003. Sixth International Conference on, pp. 491-494, ISBN: 7-5062-6210-X

Nagy, Z.; Bara, A. \& Dale, S. (2009). Control Algorithm of a BLDC Motor, Annals of DAAAM for 2009 \& Proceedings of the 20th International DAAAM Symposium, 25-28th November 2009, Vienna, Austria, ISSN 1726-9679, ISBN 978-3-901509-70-4, Katalinic, B. (Ed.), pp. 1657-1658, Published by DAAAM International Vienna, Vienna

Vorel, P. (2005). Power electromechanical systems in road vehicles., Brno, 2005. 137 p. thesis. Department of Power Electrical and Electronic Engineering, FEEC BUT 